\title{
Percentage of reward vs. N-length in the runway'
}

\author{
E. J. CAPALDI AND LARRY R. STANLEY \\ UNIVERSITY OF TEXAS
}

\begin{abstract}
Abstraet
Two groups of 13 rats each were trained in the runway for 205 trials. Group 61 received $61 \%$ rewarded trials and long $\mathrm{N}$-lengths, whereas Group 46 received $46 \%$ rewarded trials and short $\mathrm{N}$-lengths. Group 61 was more resistant to extinction than Group 46, confirming previous findings in the discrete trial operant situation. The results of the present investigation employing extensive training were contrasted with those from investigations employing small numbers of acquisition trials.
\end{abstract}

\section{Problem}

Resistance to extinction ( $\mathrm{Rn}$ ) has been shown to vary when percentage (\%) of reward was held constant. Under \% constant conditions $\mathrm{Rn}$ appears to be regulated by several variables, most notably N-length (Capaldi, 1964), defined as the number of nonrewarded (N) trials occurring in succession without interruption by a rewarded (R) trial. That $\mathrm{Rn}$ increases as \% decreases (e.g., Weinstock, 1954) also follows from N-length, since under a random assignment of $\mathrm{N}$ and $\mathrm{R}$ trials, as typically occurs, $\mathrm{N}$-length tends to increase as $\%$ decreases. If this observation is valid, it follows that a higher \% will produce greater $\mathrm{Rn}$ than a lower one provided the longer N-lengths are associated with the higher \%.

\section{Method}

The Ss were 26 Holtzman rats 80-90 days old at the beginning of the experiment, randomly divided into two groups of 13. The apparatus was a gray straightalley runway 82 in long, 4 in wide, with 9-in high sides, covered with 1/2-in hardware cloth. The initial portion of the alley was an 8-in floor treadle which, depressed by the weight of the rat, whose front paws were placed at the most forward edge, started a clock calibrated to $.01 \mathrm{sec}$. Three response measures were available (start, run, and goal times), but for the purpose of the present study the three were combined into a single measure. The terminal clock was stopped by the breaking of a photobeam 4-3/4 in from the end of the alley and 2-3/4 in in front of a brass, 2 by 4 by $1-1 / 2$ in food cup covered by a sliding lid which opened automatically when the photobeam was broken. Two identical food wells were used, one for reinforced trials (wet mash) and the other for nonreinforced trials. A manually-lowered guillotine door, 14 in from the rear of the goal compartment, served to confine $S$ to the goal area.

On Day 1 Ss were placed in large living cages. On Day 11 food deprivation began, Ss being fed wet mash for $1 \mathrm{hr}$. in the home cage throughout the experiment. On Days 16 through $18 \mathrm{Ss}$ were handled and tamed, and beginning on Day 16 Ss were placed in individual cages. Days 19 and 20 were used for goal box training. Four 30-sec. reinforced goal box placements were given each animal. On Days 21 and 22 all animals were given two reinforced runway trials.

The 20 days of acquisition training $(8,9$, or 10 trials/day) began on Day 23 (205 acquisition trials). Group 61 received $61 \%$ rewarded trials with N-length being 1,2 , or 5 , each $\mathrm{N}$-length occurring 10 times over the acquisition period. Group 46 received $46 \%$ rewarded trials with $\mathrm{N}$-lengths of 1 or $2,1 \mathrm{~N}$-length occurring 20 times, $2 \mathrm{~N}$-lengths, 45 times over the 205 acquisition trials. Thus, Group 61 received $125 \mathrm{R}$ and $80 \mathrm{~N}$ trials, while Group 46 received $95 \mathrm{R}$ and $110 \mathrm{~N}$ trials. The intertrial interval was $20 \mathrm{sec}$. and confinement was $25 \mathrm{sec}$. on $\mathrm{R}$ and $\mathrm{N}$ trials. Following acquisition five days of extinction (eight 25-sec. $\mathrm{N}$ trials/ day) were given with a 25-sec. intertrial interval. Throughout all phases of training $S$ was allowed 180 sec. to enter the goal box prior to forcing and assignment of a 180-sec. time score and was fed the daily $1-\mathrm{hr}$. ration $10 \mathrm{~min}$. following the last daily trial.

\section{Results}

Figure 1 shows the mean log total times for the two groups on the last two days of acquisition and each of the five days of extinction. Acquisition differences

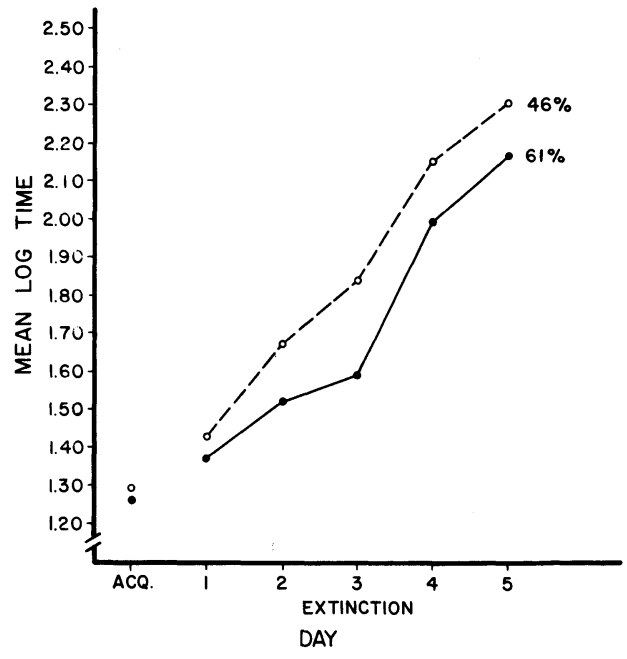

Fig. 1. Running time on the last two days of acquisition and on each of the five days of extinction. 
between the groups employing mean logs were not significant either on Day $1(F<1)$ or on the last two days of acquisition $(F<1)$. An analysis of variance employing mean logs over the five days of extinction indicated that differences were highly significant ( $\mathrm{F}=22.36, \mathrm{df}=1 / 24, \mathrm{p}<.001)$ with Group 61 showing greater Rn than Group 46.

\section{Discussion}

The results of the present investigation employing extensive acquisition training and a locomotor response in the runway are consistent with those of Gonzalez \& Bitterman (1964), who employed extensive training and discrete trials in the operant situation, and like the results of Gonzalez and Bitterman suggest that the greater Rn typically associated with lower \% is probably related to N-length. Assume that each N-length has an associated and distinctive stimulus (Capaldi, 1964). Under \% constant conditions following a relatively small number of acquisition trials, the longer N-lengths are associated not with greater but with lesser Rn. This is true for either partial reward (Capaldi, 1964; Capaldi \& Hart, 1962) or partial delay of reward (Capaldi \& Spivey, in press). These findings are deducible from an analysis of the stimulus properties associated with different $\mathrm{N}$-lengths (Capaldi, 1964). With number of $\mathrm{N}$ and $\mathrm{R}$ trials equated, shorter $\mathrm{N}$-lengths necessarily occur more often than longer ones, and thus their associated stimuli are conditioned more often. With extensive training number of conditioning trials becomes irrelevant because all S-R tendencies possess asymptotic strength and thus $\mathrm{Rn}$ is determined by $\mathrm{N}$-length alone. But, as has been shown (Capaldi, 1964), it is deducible from an aftereffects hypothesis that following a relatively small number of acquisition trials the greater strength of the stimuli associated with the longer N-lengths will outweigh the longer but more weakly conditioned N-lengths as a determiner of $\mathrm{Rn}$.

\section{References}

Capaldi, E. J. Effect of N-length, number of different N-lengths, and number of reinforcements on resistance to extinction. $J$. exp. Psychol., 1964, 68, 230-239.

Capaldi, E. J., \& Hart, D. Influence of a small number of partial reinforcement training trials on resistance to extinction. $J$. exp. Psychol., 1962, 64, 166-174

Capaldi, E. J., \& Spivey, J. E. Schedule of partial delay of reinforcement and resistance to extinction. J. comp. physiol. Psychol., in press.

Gonzalez, R. C., \& Bitterman, M. E. Resistance to extinction in the rat as a function of percentage and distribution of reinforcement. J. comp. physiol. Psychol., 1964, 58, 258-263.

Weinstock, S. Resistance to extinction of a running response following partial reinforcement under widely spaced trials. J. comp. physiol. Psychol., 1954, 47, 318-322.

\section{Note}

1. This investigation was supported in part by National Institute of Child Health and Human Development Research Grant HD 00949-02 to the first author. 